\title{
Formação docente continuada: ensino híbrido e sala de aula invertida como recurso metodológico para o aprimoramento do profissional de educação
}

\author{
Ongoing teacher development: blended learning and flipped classroom as a \\ methodological resource for the enhancement of professionals in education
}

Agnes Priscila Martins de Morais ${ }^{1}$

Priscila Franciely Souza ${ }^{2}$

\begin{abstract}
Resumo: O presente artigo elege como objeto de estudo a formação docente continuada e o uso das tecnologias digitais e das Metodologias Ativas: sala de aula invertida e ensino híbrido como recurso metodológico para o aprimoramento do docente. Parte-se do pressuposto de que no atual contexto social o ensino convencional deve ser repensado, para que possibilite que os alunos sejam sujeitos ativos e autônomos do seu próprio processo de ensino-aprendizagem. Observa-se que o paradigma educacional necessita de transformações, assim como as mudanças ocorridas na sociedade devido ao uso das tecnologias digitais cada vez mais presentes. Desse modo, o presente trabalho tem como objetivo evidenciar a relevância da formação docente continuada que promova o uso das tecnologias digitais em busca de mudanças nas práticas pedagógicas por meio do trabalho com as Metodologias Ativas. Para a consecução deste estudo proposto, foi realizada uma pesquisa teórica que buscou embasamentos fundamentais para promover tal reflexão. Nesse sentido, o trabalho se justifica pela necessidade de propor uma reflexão sobre a importância das TDIC e as Metodologias Ativas para o aprimoramento do profissional de educação e uma formação de alunos autônomos, mais críticos e reflexivos contribuindo com a sua formação cidadã. A reflexão deste estudo teve como objetivo incentivar futuros pesquisadores a utilizarem em suas aulas recursos mais interativos visando outras direções em relação ao ensino-aprendizagem.
\end{abstract}

Palavras-chave: Ensino Híbrido; Sala de Aula Invertida; Formação de Professores; Metodologias Ativas.

\begin{abstract}
This article chooses as an object of study the ongoing teacher development and the use of digital technologies and active learning: blended learning and flipped classroom as a methodological resource for the improvement of the teacher. It is assumed that in the current social context, conventional education must be rethought, so that it is able to promote that students are active and autonomous subjects of their own teaching-learning process. It is observed that the educational paradigm needs changes, as well as the resulting changes in society due to the use of digital technologies increasingly present. Thus, the present work

\footnotetext{
${ }^{1}$ Mestre em Educação, Universidade Federal de Lavras, Divinópolis, Minas Gerais, Brasil, agnes.pri@gmail.com

${ }^{2}$ Mestre em educação, Universidade Federal de Lavras, Lavras, Minas Gerais, Brasil, prifranciely@gmail.com
} 
aims to highlight the relevance of ongoing teacher development that promotes the use of digital technologies in search of changes in pedagogical practices through working with active learning. To carry out this proposed study, a theoretical research was carried out that sought fundamental foundations to promote such reflection. In this sense, the work is justified by the need to propose a reflection on the importance of TDIC and active learning for the improvement of education professionals and the training of autonomous students, who are more critical and reflective, contributing to their citizenship formation. The reflection of this study aimed to encourage future researchers to use more interactive resources in their classes, aiming at other directions in relation to teaching-learning.

Keywords: Blended Learning; Flipped Classroom; Ongoing Teacher; Active Learning.

\section{Introdução}

Em decorrência das transformações ocorridas no contexto atual, em uma época globalizada e cada vez mais tecnológica, é necessário considerar ao iniciar este artigo que o uso das atuais tecnologias digitais está cada vez mais recorrente no cotidiano dos indivíduos. Desse modo, o modelo educacional necessita de uma nova abordagem, visto que devido à pandemia do COVID 19 em 2020, parte do ensino básico do país foi realizado de forma online (grande parte dos estudantes, em especial de instituições públicas, ficaram sem nenhuma modalidade de ensino nessa época). Observa-se, diante desse cenário, que um novo paradigma surge na educação no qual exigem novas posturas do professor ao se revelar a importância da formação docente continuada, uma vez que o docente precisa estar atualizado e preparado para incorporar as Metodologias Ativas com o apoio das tecnologias digitais em sala de aula.

Dessa maneira, o presente artigo busca evidenciar que o ensino tradicional deve ser repensado no que se refere à contribuição de maneira positiva no processo de ensinoaprendizagem dos alunos, uma vez que o aluno não pode ser considerado como um objeto passivo, mas sim como sujeito ativo desse processo. Nesse sentido, apenas a transmissão do que o professor sabe para o aluno não se faz suficiente, pois é necessário que o aluno seja motivado, estimulado e incentivado pelo docente em um ensino que tenha a interação presente entre a construção e troca do conhecimento entre professor, aluno e seus colegas de sala, além de considerar o contexto dos mesmos visando o exercício da crítica e reflexão, que lhes serão essenciais na vida em sociedade. 
Sendo assim, é relevante destacar que o profissional de educação, ao trabalhar com uma visão de ensino mais inovadora mediante ao uso de Metodologias Ativas, no qual partese do ensino-aprendizagem por meio de desafios, de projetos, de pesquisas, de jogos, seja individual ou em grupo, é capaz de estimular os alunos tornando-os ativos na construção do conhecimento e reflexão do seu processo de ensino-aprendizagem (MITRE et al. 2008). Nesse sentido, é por meio das Metodologias Ativas que os alunos mediante a um problema e situações reais buscam por soluções de modo que são capazes de aprender por intermédio da prática.

Em relação às Metodologias Ativas, sabe-se que existem diversas utilizadas no processo de ensino-aprendizagem, porém, este estudo dará foco ao ensino híbrido e à sala de aula invertida, Metodologias Ativas as quais utilizam, principalmente, recursos tecnológicos. Cabe ainda mencionar que ao trabalhar com as Metodologias Ativas o professor é de extrema relevância na construção do conhecimento, visto que devido a disseminação das tecnologias digitais e o acesso instantâneo a diversas informações é o docente que irá orientar os seus alunos para que as informações adquiridas se tornem conhecimento e será o intermediador para integrar a questão do ensino-aprendizagem presencial com o virtual colaborando com a autonomia dos alunos (VALENTE, 2018).

Diante das considerações no que diz respeito à necessidade de uma formação docente continuada e consequentemente em mudanças no cenário educacional, o artigo pretende explanar algumas possíveis contribuições das Metodologias Ativas apoiada ao uso das tecnologias digitais, com o intuito de conhecer e disseminar metodologias que possam contribuir para uma formação mais dinâmica do professor, com vistas a estimulá-lo à adoção de metodologias mais participativas em sala de aula com o intuito de propiciar aos alunos uma formação mais crítica e reflexiva de futuros profissionais das mais diversas áreas.

\section{A importância da formação docente continuada}

Levando em consideração as constantes mudanças da sociedade, principalmente devido ao uso da tecnologia, não se pode deixar de lado a questão da quantidade avançada de informações que se tem atualmente e a sua rápida disseminação. Dessa forma, entra em questão a distinção entre a informação e o conhecimento, na qual cabe a importância da função do docente em transformar a informação em conhecimento para os seus alunos, ou 
seja, torna-la significativa.

Bagno (2009) discorre a esse respeito afirmando que a função de um professor não se restringe a mera transmissão de conteúdos, mas sim "ensinar a aprender" criando oportunidades para que os estudantes sejam preparados para buscar aquilo que ainda é desconhecido. Por essa razão, a função de um docente é de orientar, de direcionar, de conduzir os seus alunos para que sejam capazes de desenvolver a capacidade de criticar e de refletir diante de uma informação. Sendo assim, é necessário que o educador seja um mediador do conhecimento e não monopolizador, de modo que possa compreender que o aluno não é objeto e sim o sujeito do processo de ensino-aprendizagem, e que existe uma troca de conhecimentos por meio da interação entre ambos (professor-aluno).

Nesse viés, a formação do docente necessita ser bem consolidada e constante, uma vez que a função do educador acarreta não somente com a dimensão educacional, mas também com a dimensão social mediante ao ensino que realiza. Consequentemente, o professor deve capacitar-se para que suas aulas não detenham apenas de métodos tradicionais de ensino para que disponha de novas metodologias e temas de acordo com a sociedade e comunidade, estimulando os estudantes em busca de uma educação interativa e satisfatória.

Diante dessa questão, entende-se que um ensino reprodutivista, no qual as informações são apenas transmitidas aos alunos em um modelo tradicional, sem que haja uma reflexão e interação atualmente não é capaz de gerar conhecimento. Conforme Volpi (2001, p.134) no que se refere a essa mudança que o docente precisa fazer em suas práticas pedagógicas por intermédio de uma prática reflexiva, argumenta que:

Numa nova visão da função docente, o professor há de ser um indivíduo consciente de que ele não é o detentor do monopólio do saber, de que o conhecimento, por ser multifacetado, representa um permanente desafio às suas crenças e convicções: de que o ser humano está em constante processo de aprendizagem, e, consequentemente, a sua responsabilidade não se limita à transmissão de informações, mas deve atender a funções sociais mais abrangentes.

Dessa forma, é possível notar que quando alguns docentes se estagnam em sua formação inicial não conseguem colaborar efetivamente no processo de desenvolvimento humano, visto que assim como na sociedade ocorrem transformações rotineiramente, no processo de ensino-aprendizagem não se faz diferente. Sendo assim, a formação do professor deve levar em consideração uma perspectiva reflexiva e contínua pautada na multiplicidade 
dos contextos sociais nos quais os alunos estão inseridos.

Entretanto, para que de fato essa formação seja contínua deve-se ter como propósito uma metodologia interativa, que tenha como objetivo uma construção crítica reflexiva, na qual possibilite ao professor investigar e transformar a sua prática pedagógica em sala de aula. Nessa perspectiva, segundo Antunes (2006), uma formação que permita partir das teorias existentes e da construção de novas teorias, dos saberes docentes, dos valores e dos modos de conceber o mundo e de ser no mundo.

Nesse sentido, a formação docente continuada se faz necessária visto que busca romper com visões de ensino tradicionais, que conforme Gerhardt (p.78-79,2013) acarreta a "invisibilidade da pessoa do aluno e a consequente ausência de atenção aos seus processos de subjetivação, bem como das semioses que ele produz dentro e fora de sala de aula”. Por essa razão, apenas a formação inicial não se faz suficiente para um professor, uma vez que a prática pedagógica também se caracteriza pelo contexto formativo no qual envolve diversos fatores como sujeitos, situações, motivações, conhecimentos prévios o que fazem com que as suas práticas se alterem em relação as suas experiências vivenciadas.

Desse modo, a falta da constante formação pode acarretar que os professores aceitem sem questionar determinados conceitos e normas que foram aprendidos em sua formação inicial e não busquem conhecer e compreender as novas metodologias e conceitos atuais. Portanto, a formação continuada permite ao educador a aquisição de conhecimentos característicos da profissão, tornando-se assim seres mais habilitados a atender as imposições impostas pela sociedade, exigências estas que se transformam com o passar dos tempos, tendo então o docente que estar constantemente atualizado. Em relação a essa inovação Sousa afirma que:

Ser professor, hoje, significa não somente ensinar determinados conteúdos, mas sobretudo um ser educador comprometido com as transformações da sociedade, oportunizando aos alunos o exercício dos direitos básicos à cidadania. (SOUZA, 2008, p.42)

Vale advertir que é mediante a formação constante que o professor no exercício da prática docente poderá compreender a necessidade das alterações realizadas no que se refere ao âmbito educacional. Desse modo, com o objetivo de visar o papel do aluno como sujeito ativo do processo de ensino-aprendizagem, para que assim possa se tornar um cidadão crítico 
e reflexivo, que saiba se posicionar e argumentar mediante a sociedade.

Discorrendo sobre a temática da formação docente continuada, Imbernón pontua que:

A formação continuada deveria apoiar, criar e potencializar uma reflexão real dos sujeitos sobre sua prática docente nas instituições educacionais e em outras instituições, de modo que lhes permitisse examinar suas teorias implícitas, seu esquema de funcionamento, suas atitudes, estabelecendo de forma firme, um processo constante de autoavaliação do que se faz e porque se faz (...) (IMBERNÓN, 2010, p. 47).

A partir da afirmação do autor, é válido ressaltar que a formação continuada de fato só será efetiva, se não tiver como princípio somente a atualização científica e didática adquirida por meio de certificados e de teoria, uma vez que essa formação constante deve ser muito mais ampla e reflexiva. Consequentemente, a formação docente continuada satisfatória dispõe de auxiliar os professores a compreender a sua metodologia utilizada em sala de aula, analisar, refletir, questionar e ser capaz de modifica-la, de construí-la ou até mesmo de reconstruir.

Em consonância com essa postura de uma formação contínua que não seja efetiva, Magalhães adverte que:

Geralmente, esses cursos oferecem ao aluno-professor um "pacote" de novidades e receitas que acabam por não transformar sua prática, pois a visão do mundo, homem, linguagem, ensino-aprendizagem são pouco modificadas. (MAGALHÃES, 2001, p.242)

Em face ao exposto, não é necessário apenas a mera apresentação de conceitos teóricos, modelos de práticas pedagógicas “inovadoras”, é fundamental fazer com que a visão dos professores no que diz respeito a questão do ensino-aprendizagem seja modificada. Desse modo, não é preciso somente o conhecimento teórico, mas também a incorporação desse conhecimento no cotidiano, ou seja, na prática docente.

Tendo em vista a importância da formação docente continuada, vale ressaltar que o verdadeiro propósito dessa constante formação é observar e acompanhar o avanço dos docentes a partir da apropriação dos conhecimentos adquiridos, da associação entre a teoria e a prática. Sabe-se que, o embasamento teórico é fundamental para propiciar uma reflexão no professor, para que seja possível modificar a sua realidade se posicionando como um sujeito de sua ação que é capaz de refletir na e sobre a suas intervenções/práticas com o objetivo de contribuir para o processo de ensino-aprendizagem. 
Cabe ainda mencionar que, a formação continuada significativa que de fato possibilite novos direcionamentos na profissão docente deve se basear não apenas em conceitos teóricos, mas também da análise e discussão da prática, uma vez que é por intermédio dessa junção que irá possibilitar a reflexão. Em relação a essa questão Imbernón menciona que:

O conhecimento profissional consolidado mediante a formação permanente apoia-se tanto na aquisição de conhecimentos teóricos e de competências de processamento da informação, análise e reflexão crítica em, sobre e durante a ação, o diagnóstico, a decisão racional, a avaliação de processos e a reformulação de projetos (IMBERNÓN, 2010, p.75).

Mediante ao exposto, o que se observa é que o processo de formação continuada permite o amadurecimento profissional, mas, sobretudo desenvolve a capacidade reflexiva do docente levando-a uma consciência coletiva e fazendo com que as mudanças possam ser feitas diante das dificuldades encontradas no plano escolar. Além disso, o autor ressalta mais uma vez a importância da obtenção da teoria para que a mesma possa colaborar com os questionamentos feitos ao se analisar a prática pedagógica.

Diante das considerações apresentadas, é importante destacar que a formação continuada que com embasamento teórico possibilita ao professor analisar a sua prática é capaz de possibilitar que o docente conheça novas metodologias de ensino-aprendizagem, para que consiga ressignificar suas estratégias/práticas metodológicas levando em consideração o contexto social em que os alunos estão inseridos. Nessa perspectiva, o docente que se mantém em constante formação tem como intuito colaborar efetivamente no processo de construção do conhecimento de seus alunos, ao desempenhar sua profissão cumprindo com o seu papel social que é de extrema relevância. A partir desse panorama, parte-se para o próximo tópico que irá abordar a formação para o ensino utilizando as tecnologias digitais.

\section{A formação docente para o uso das tecnologias digitais}

No contexto de uma época cada vez mais tecnológica, em que as tecnologias digitais, (aparelhos celulares, tablets, smartphones, computadores, notebooks, televisores, entre outros) se fazem cada vez mais presentes não se pode negar que novas formas de interação entre os indivíduos também está ocorrendo em uma era globalizada. Sendo assim, nota-se que diversos setores da sociedade passaram e ainda irão passar por essas transformações. Por essa razão, devido a disseminação das novas tecnologias digitais é necessário compreender que não se pode desconsiderar a exigência de uma nova abordagem também na área da educação. 
Antigamente o material escolar de um aluno se resumia em cadernos, livros, lápis canetas e borracha, atualmente foram incorporados outros dispositivos/apetrechos que para eles são tão indispensáveis quanto o caderno e o livro pelos professores. Desse modo, observa-se um novo cenário no qual já é realidade que alguns alunos, adentram nas escolas com um smartphone e o inseparável fone de ouvido. Diante desse contexto, nota-se que um novo paradigma surge na educação, o qual exige novas posturas do profissional da educação evidenciando a necessidade de o professor estar preparado para lidar com as novas tecnologias incorporando as em sua prática pedagógica.

Nessa perspectiva, Lévy (1993, p.7) menciona que "novas maneiras de pensar e de conviver estão sendo elaboradas no mundo das telecomunicações e da informática", uma vez que as constantes inovações nos dispositivos informacionais de todos os tipos modificam as relações entre o ser humano, o trabalho e a inteligência. Sendo assim, é possível constatar a relevância da formação continuada, a qual seja capaz de contemplar habilidades e as competências relacionadas aos usos das Tecnologias Digitais de Informação e Comunicação (doravante, TDIC) para uma atuação proficiente no encaminhamento da prática pedagógica.

No tocante à questão das tecnologias os Parâmetros Curriculares Nacionais (PCN) mencionam que:

\footnotetext{
A tecnologia é um instrumento capaz de aumentar a motivação dos alunos, se a sua utilização estiver inserida num ambiente de aprendizagem desafiador. Não é por si só um elemento motivador. Se a proposta de trabalho não for interessante, os alunos rapidamente perdem a motivação. (BRASIL,2001, p.157)
}

Nota-se que, apenas o uso da tecnologia não contribui significante na aprendizagem, visto que, se a aula não for bem planejada e não dispuser de um objetivo específico não irá motivar e muito menos auxiliar no processo cognitivo dos alunos. Abarcando a posição dos Parâmetros Curriculares Nacionais, Valente (1999, p. 19) afirma que "a questão da formação do professor mostra-se de fundamental importância no processo de introdução da informática na educação, exigindo soluções inovadoras e novas abordagens que fundamentam os cursos de formação".

Libâneo compartilha o mesmo pensamento, ao argumentar que a formação docente demanda acompanhar as transformações ocorridas na sociedade que

[...] presentemente, ante novas realidades econômicas e sociais, especialmente os avanços tecnológicos na comunicação e informação, novos 
sistemas produtivos e novos paradigmas do conhecimento, impõem se novas exigências no debate sobre a qualidade da Educação e, por consequência, sobre a formação de educadores. (LIBÂNEO, 2008 p. 40)

Em relação ao docente perceber a necessidade de mudanças e da inserção das TDIC no âmbito escolar, Bagno postula:

O importante é mostrar aos alunos que existe na escola uma vontade de acompanhar as transformações que estão se processando do lado de fora da sala de aula e que todos os meios e multimeios oferecidos pelas novas tecnologias, também devem ser usados para tornar o aprendizado mais atraente, mais atualizado, mais vivo. (BAGNO,2009, p.62)

A partir das afirmações dos autores citados, ressalta-se que é por intermédio da interação do professor com os alunos e da prática pedagógica adotada pelo docente, que a pesquisa possa se tornar presente com o objetivo de estimular os alunos na busca do conhecimento, sendo sujeitos do seu processo de ensino-aprendizagem. Nesse sentido, o que é construído, pensado e refletido permite a compreensão e melhor assimilação do que simplesmente uma aula teórica sem interação e sem reflexão. Vale ressaltar, que o docente que utiliza em suas aulas das TDIC que não seja em paradigma da educação tradicional, pode conseguir proporcionar maior interação, uma vez que a utilização desses recursos por exemplo os smartphones dos alunos propiciam maior envolvimento e interesse, além do fato de que nesse caso a aprendizagem não é transmitida, mas sim construída entre o que o professor sabe e o que os alunos o ensinam mediante as pesquisas e descobertas realizadas ao navegar na web.

Ampliando essa questão Lévy (1999, p.172) considera que "O uso crescente das tecnologias digitais e das redes de comunicação interativa acompanha e amplifica uma profunda mutação na relação com o saber". Por esse aspecto, não é mais possível que os docentes neguem que a tecnologia digital é uma realidade que influência na sociedade, mas também no comportamento do aluno em sala de aula. Portanto, é crucial que o professor possa perceber que o ensino por meio das suas práticas pedagógicas aliado com a tecnologia digital trará melhores resultados do que a proibição da mesma.

Devido a esse contexto atual, no qual as transformações tanto sociais, políticas e tecnológicas são constantes, sabe-se que o número de informações que se obtém em questão de segundos com o uso das tecnologias digitais é exorbitante. Diante dessa questão, fica evidente a responsabilidade que o educador necessita ao saber conduzir seus alunos de modo que seja capaz de orientá-los com um olhar crítico sobre aquilo que leem e não simplesmente 
tomar como uma verdade inquestionável. Em consequência do grande número de informações que a internet propicia, também aumentou se o número de desinformação.

Em vista disso, o docente deve estar preparado para atuar nesse contexto de mudança com a presença de tantas informações com fácil acesso, de modo que seja capaz de conduzir seus alunos a saberem como pesquisar e verificar as informações encontradas. Em relação a isso, Valente assegura que:

\begin{abstract}
A internet está ficando cada vez mais interessante e criativa, possibilitando a exploração de um número incrível de assuntos. Porém, se o aprendiz não tem um objetivo nesta navegação ele pode ficar perdido. A ideia de navegar pode mantê-lo ocupado por um longo período de tempo, porém muito pouco pode ser realizado em termos de compreensão e transformação dos tópicos visitados em conhecimento. Se a informação obtida não é posta em uso, se ela não é trabalha da pelo professor, não há nenhuma maneira de estarmos seguros de que o aluno compreendeu o que está fazendo. Nesse caso, cabe ao professor suprir essas situações para que a construção do conhecimento ocorra. (VALENTE,1999, p.13)
\end{abstract}

Dessa maneira, mesmo com o uso das TDIC, o professor continua a ser uma figura fundamental, uma vez que será o mediador do processo, aquele que irá mostrar o caminho, estimular os alunos, ajudar a interpretar e contextualizar as informações, além de apoiar os mesmos sejam em trabalhos em grupo ou individuais, para que os alunos possam desenvolver diferentes habilidades. Portanto, o docente é responsável por motivar a aprendizagem, usufruindo da tecnologia como um importante auxílio para promover o ensino de novas e significativas aprendizagens. Observa-se assim, que o uso das TDIC propicia uma mudança positiva no âmbito educacional, desde que o docente esteja preparado para trabalhar com tais recursos, ao promover que o espaço de ensino-aprendizagem seja atrativo, motivador e interativo para a construção do conhecimento.

As postulações disponibilizadas nesse tópico, permitem assegurar que o modelo educacional mudou mediante ao impacto significativo das tecnologias digitais e que estas não podem ser desconsideradas. Nesse sentido, se reforça a necessidade da qualificação profissional para que as práticas pedagógicas sejam reformuladas visando os benefícios da aprendizagem com tecnologias digitais, ao propiciar que os alunos sejam ativos no processo de ensino-aprendizagem.

Vale ressaltar, a necessidade nesse processo do auxílio do professor em transformar informação em conhecimento, incentivando os alunos a participarem de experiências diferentes. Nesse sentido, é importante aproximar a educação da realidade dos alunos ao 


\section{OO DEVIR EDUCAÇÃO}

ISSN: 2526-849X

permitir que com o uso das TDIC de forma apropriada, os alunos se tornem cidadãos conscientes, pensantes e atuantes de maneira construtiva na sociedade. Para que isso aconteça de forma profícua, um das estratégias apresentadas neste estudo é o uso de metodologias ativas, que nortearão o docente a respeito dos possíveis caminhos para atingir seus objetivos.

\section{As Metodologias Ativas}

Quando observados e conhecidos profundamente, os contextos escolares apresentam inúmeros desafios aos docentes em exercício, isso porque, muitas vezes existem salas de aulas mal estruturadas, falta de recursos financeiros vindos do governo ou dos administrados das instituições, alunos descomprometidos com a escola e com a sua aprendizagem etc., por esses motivos, é muito importante que sejam conhecidas as necessidades de cada contexto social (dos professores e alunos) bem como sejam analisadas as transformações demandadas nas propostas curriculares e nas metodologias de ensino.

Nesse sentido, considera-se o papel fundamental de Universidades que oferecem cursos de formação continuada, um espaço que pode contribuir de forma significativa nesse processo de paradigmas, ao promover ações que possibilitam a construção coletiva de uma nova forma de interagir e de trabalhar com o conhecimento; e que conduza à compreensão da complexidade da vida humana, pela construção de um currículo mais flexível, pensado, criado e vivenciado coletivamente.

Acredita-se então, na relevância dos usos de metodologias diferenciadas, que promovam o uso significativo das TDIC. Para isso, serão explanadas algumas possíveis contribuições das Metodologias Ativas para a formação continuada de professores, com o intuito de conhecer e disseminar metodologias que possam contribuir para uma formação mais dinâmica do professor, com vistas a estimulá-lo à adoção de metodologias mais participativas em sala de aula.

Mas antes, é de suma importância conhecer o conceito de Metodologias Ativas (doravante, MA) que, segundo Valente (2018, p. 27) podem ser compreendidas como “alternativas pedagógicas que colocam o foco do processo de ensino e de aprendizagem no aprendiz, envolvendo-o na aprendizagem por descoberta, investigação ou resolução de problemas". Por esse motivo, "pesquisadores contemporâneos têm (...) procurado desenvolver 
metodologias que sejam capazes de levar à autonomia do discente e ao autogerenciamento e corresponsabilidade pelo seu próprio processo de formação" (SILVIA PINTO, 2012, p. 79).

O emprego dessas metodologias em situação de ensino-aprendizagem pode favorecer a autonomia do estudante, despertando a curiosidade, estimulando tomadas de decisões individuais e coletivas, advindos das atividades essenciais da prática social e em contextos do aluno. "Outra característica desse modelo pedagógico inovador, é o de aprender fazendo, onde a produção do conhecimento está vinculada aos cenários da vida real" (WALL et al. 2008, p.516).

No mesmo sentido, Berbel (2011, p. 29) acredita que "as Metodologias Ativas baseiam-se em formas de desenvolver o processo de aprender, utilizando experiências reais ou simuladas, visando às condições de solucionar, com sucesso, desafios advindos das atividades essenciais da prática social, em diferentes contextos". Por meio das MA, acredita-se que seja possível tornar a escola um ambiente casa vez mais democrático, uma vez que elas têm como um dos objetivos a proposta de trazer para vivência dos alunos em situações do dia a dia.

Apresentando uma visão análoga, Freitas (2009) acredita que as metodologias ativas funcionam com maneiras de desenvolver o processo do aprender que os docentes usam para levar a formação mais crítica e reflexiva de futuros profissionais das mais diversas áreas. Para ele, a utilização das MA parece favorecer a autonomia do estudante, despertando a curiosidade, na busca por tomadas de decisões individuais e coletivas, ocorridos e atividades essenciais da prática social em contextos do estudantes.

É possível acreditar que, com a utilização de MA surjam novos desafios e que as atividades possam ser planejadas, acompanhadas e avaliadas com apoio das TDIC. Esses desafios bem planejados ajudam a desenvolver competências como: intelectuais, emocionais, pessoais e comunicacionais. Por esses motivos, as MA exigem trabalho com pesquisas, avaliação de situações, de pontos de vista diferentes, fazendo escolhas, assumindo riscos, aprendendo por meio da descoberta e, por fim, caminhando do simples para o complexo (MORAN, 2015). Assim, "as metodologias ativas são pontos de partida para avançar para processos mais avançados de reflexão, de integração cognitiva, de generalização, de reelaboração de novas práticas” (MORAN, 2015, p.18).

Ampliando essa discussão, é necessário compreender que "as metodologias ativas estão alicerçadas em um princípio teórico significativo: a autonomia, algo explícito na invocação de Paulo Freire" (MITRE et al., 2008, p. 2135). Para Freire (2006), isso acontece a 
partir da liberdade, em outras palavras, no processo de reflexão e problematização de situações reais e na busca por soluções aplicáveis ao cotidiano.

Nesse entendimento, os cursos de formação poderiam articular em suas discussões experiências práticas na formação do profissional, de maneira a problematizar e simular problemas e situações da realidade, ensinando aos estudantes a responderem questões práticas de suas profissões e desenvolverem recursos para problemas futuros que poderão aparecer. Dessa maneira, Gomes et al (2010, p. 187) propõem "um processo de aprendizagem que permita aos estudantes a aquisição de conhecimentos teóricos, com base na observação da realidade e na reflexão crítica sobre as ações dos sujeitos, de forma que os conteúdos teóricos sejam apreendidos em conexão com a prática”.

Sabe-se, portanto, que as metodologias ativas podem trazer ganhos positivos. Diante de tal colocação, Berbel (2011) elenca alguns benefícios que podem ser gerados por meio de trabalhos que envolvam as MA, são eles:

- Os alunos é que problematizam a parcela da realidade associada ao foco do estudo, selecionam um dos problemas para estudar e buscam uma resposta ou uma solução para ele;

- Considera-se a realidade concreta para aprender com ela e para nela intervir, em busca de soluções para seus problemas;

- A participação do aluno se dá no exercício do aprender fazendo;

- A relação teoria-prática é constante;

- A vivência desse caminho metodológico pelos alunos permite-lhes a construção de conhecimentos;

- O processo se completa com algum grau de intervenção;

- O fato de os alunos, desde o início, analisarem criticamente uma parcela da realidade para problematizá-la e, diante das diferentes possibilidades, elegerem aquele aspecto que consideram mais relevante para o estudo naquele momento;

- Os alunos vão sendo estimulados a confirmarem suas crenças, seus valores e seus conceitos anteriores, ou a colocá-los em dúvida, ou até reformulá-los, pelos novos aprendizados;

- Todo o processo desenvolvido permite tomar consciência da complexidade dos fenômenos sociais envolvidos no estudo;

- O estímulo ao desenvolvimento do pensamento crítico;

- Os alunos são também mobilizados para aprendizados sociais, políticos e éticos, que contribuem para a formação do ser cidadão;

- A avaliação, nesse processo, portanto, é essencialmente formativa. (BERBEL, 2011, p. 33-35).

A partir das afirmações dos autores, é necessário afirmar que as MA podem ser úteis não apenas para propiciar aos estudantes aulas mais dinâmicas e atualizadas, a partir do uso 
das TDIC, mas também na promoção de alunos autônomos, em exercício da crítica e reflexão, que lhes serão essenciais na vida em sociedade.

\section{Formação de professores para às Metodologias Ativas}

Uma educação transformadora é aquela que, sem dúvidas, traga ganhos e dialogue com a realidade social vigente. Entretanto, para que isso aconteça efetivamente, novas metodologias de ensino deveriam ser trabalhadas no contexto escolar, com o intuito de melhorar a qualidade de vida e dialogar com o contexto social em constante transformação.

Entretanto, essa visão transformadora parece exigir mudanças didáticas nos currículos, pois estes estão sobrecarregados de conteúdos insuficientes para a vida profissional na atualidade dado os problemas sociais vigentes, necessitando de habilidades além do conhecimento específicas de cada área, tais como: colaboração, conhecimento interdisciplinar, habilidade para inovação, trabalho em grupo, educação para o desenvolvimento sustentável, regional e globalizado (GEMIGNANI, 2012).

Prova disso foi o enorme choque provocado em todo sistema educacional brasileiro em 2020, ano em que boa parte do ano letivo, em inúmeras escolas no Brasil, foi feito de forma on-line, devido a pandemia do COVID 19 na maioria dos países do planeta. Esse contexto veio mostrar ainda mais a necessidade de formação inicial e continuada de professores para o uso da TDIC e das Metodologias Ativas, com intuito de capacitar os professores e dinamizar suas práticas pedagógicas.

Apresentando um argumento mais abrangente, destaca-se, em conformidade com Freitas et al, que:

\footnotetext{
os métodos e os recursos do processo de ensino e aprendizagem são variados. As informações mais recentes eram, até pouco tempo atrás, baseadas em periódicos. No entanto, com a evolução da tecnologia, ocorreram transformações na dinâmica da troca do saber. Como as teorias precisam ser renovadas ou confirmadas constantemente, para acompanhar essa dinâmica o processo de ensino e aprendizagem deve estar em contínua avaliação, a fim de manter a par das descobertas científicas (FREITAS et al. 2009, p. 164).
}

Nessa direção, pode-se compreender que "a educação contemporânea requer de docentes e discentes a atitude da corresponsabilidade e autogestão em relação ao processo da aprendizagem. Nesse sentido, é necessário que as instituições de ensino superior promovam inovações didáticas que tornem a aprendizagem significativa" (SILVIA PINTO, 2012, p. 76). 
Para elucidar o exposto, pode-se fazer referência ao posicionamento de Barbosa e Moura (2013), que acreditam que por essa geração conviver com mais facilidade com os métodos ativos de aprendizagem no dia a dia escolar, será possível deixar para trás um dos grandes desafios pedagógicos dos dias atuais, que é incorporar a aprendizagem ativa no contexto escolar. Segundo eles, é justamente no espaço da sala de aula, nas relações entre o professor e os alunos que são mais necessárias que ocorram essas transformações.

Proporcionando uma visão numa perspectiva mais ampla e direcionando para a questão da formação, pode-se afirmar que, segundo Morán (2015), o papel do professor vai além de "curador ou orientador". Curador é aquele que seleciona o que é mais importante diante de tanta informação disponível e os auxilia na escola de materiais e atividades que sejam relevantes. Além disso, ele é quem vai orientar a classe, os grupos e cada estudante individualmente. Esse professor deve ser capaz de agir intelectualmente, afetivamente e gerencialmente. Tudo isso vai exigir uma formação mais aperfeiçoada, uma profissão mais valorizada e salários que sejam condizentes com a carga horária de trabalho mais justa.

Nessa perspectiva, Bonwell e Eison (1991, apud, BARBOSA; MOURA, 2013) afirmam que a existência de diferentes estratégias que possibilitam o uso de MA em sala de aula. Entre elas, pode-se destacar discussão de temas e tópicos para aperfeiçoamento da formação docente; utilização de trabalho trabalhos em equipe, que exigem a unidade de todos; estudos de caso na área de formação de professores; discussão a respeito de temas da atualidade; criação de ideias (brainstorming) para solucionar problematizações; construção de mapas conceituais com o intuito de explicar conceitos e ideias; simulação de situações reais para exemplificar questões cotidianas; geração de sites ou redes sociais para aprendizagens cooperativas e, por fim, criação de questões de pesquisa na área científica e tecnológica formativa.

Apresentando uma visão análoga, Berbel (2011) afirma que a inclusão dessas metodologias pode favorecer o desenvolvimentos de processos de aprendizagem bem mais autônoma, no sentido de serem apresentadas ao estudante oportunidades de problematização de situações do cotidiano da escola.

Nesse sentido, o uso de MA parece favorecer a autonomia do estudante, pois as atividades diferenciadas podem acabar despertando a curiosidade, levando-o a buscar mais informações e conhecimentos de maneira a exercer a autonomia. Os elementos trazidos a partir do exercício da autonomia podem ser um auxiliador do professor na busca de novas 
perspectivas sobre a temática tratada em sala de aula e isso pode acabar por estimular ainda mais a participação dos alunos. Assim, "educar para a autonomia significa também, consequentemente, um ato político e para o campo de formação profissional e ou formação de professores, um ato político pedagógico" (BERBEL, 2011, p.30).

Ampliando esse pensamento, pode-se em conformidade com Berbel, defender que:

as alternativas de metodologias ativas elencadas neste item colocam o aluno diante de problemas e/ou desafios que mobilizam o seu potencial intelectual, enquanto estuda para compreendê-los e ou superá-los. Os estudantes necessitam de informações, mas são especialmente estimulados a trabalhar com elas, elaborá-las e reelaborá-las em função do que precisam responder ou equacionar. Nesse caminho, é possível que ocorra, gradativamente, o desenvolvimento do espírito científico, do pensamento crítico, do pensamento reflexivo, de valores éticos, entre outras conquistas dessa natureza, por meio da educação, nos diferentes níveis, contribuindo para o desenvolvimento da autonomia na formação do ser humano e de futuros profissionais (BERBEL, 2011, p.34).

Nessa perspectiva, a utilização de metodologias ativas exige do docente um ensino mais flexível e com maior habilidade de articulação, pois elas são ferramentas para transformarem os indivíduos e eles transformarem o contexto a sua volta. Por isso, "as técnicas de ensino devem possibilitar que se trabalhe (...) estimulando a comunicação, o trabalho em equipe, (...) bem como as formas de convivência, permitindo a manifestação e levando em conta o tempo de aprendizagem de cada aluno" (WALL et al. 2008, p.516).

Ainda discorrendo sobre a temática, é possível acrescentar que para os autores supracitados, quando o processo que envolve o ensino-aprendizagem acontece por meio da utilização de metodologias ativas, o estudante passa a ter o papel principal no seu aprendizado e o docente se torna o mediador ou facilitador desse conhecimento. Por isso, incluir as MA em processos de formação continuada pode trazer inúmeros desafios, como por exemplo, questões estruturais das entidades até as transformações de conceitos pedagógicos nos docentes e nos estudantes- crenças, valores, modos de fazer, ensinar etc.

Desse modo, o trabalho com as MA pode surgir como uma importante estratégia metodológica na formação de professores mais aptos a responderem às novas demandas sociais. Nesse sentido, além de responder ao contexto vigente, os docentes em formação, podem ter uma consciência social transformada, no sentido de não formar futuros profissionais de forma "mecanizada ou normativa" mas sim, buscando revelar a individualidade de cada um e promover a reflexão e conscientização social, tão importantes para o sucesso profissional de qualquer que seja a profissão. 
Sabe-se uma gama de MA existentes e utilizáveis no processo de ensinoaprendizagem. Entretanto, este estudo dará foco ao ensino híbrido e à sala de aula invertida, metodologias ativas as quais utilizam, principalmente, recursos tecnológicos.

\section{Ensino Híbrido e Sala de Aula Invertida}

No contexto vigente, um dos grandes desafios da escola e dos professores é dialogar com as significativas mudanças que vêm ocorrendo na sociedade. Tais mudanças aconteceram, principalmente, devido às TDIC e o desafio se torna ainda maior quando observa-se a necessidade de toda comunidade escolar dialogar com esse cenário e afim tornalo relevante.

Sabe-se que há diversas dificuldades (problemas com infraestrutura, financiamento público e privado, formação eficiente de professores) e desafios necessários na promoção de uma pedagogia diferenciada, mas essas dificuldades têm sido superadas à medida que as tecnologias vêm sendo usadas em processos educacionais e em salas de aula, contudo, "implantar infraestrutura tecnológica nas escolas é apenas parte da inclusão das TIC na educação.” (BARBOSA; MOURA, 2013, p. 6). Utilizar essas tecnologias de maneira significativa requer esforço e empenho do docente, na medida em que ele precisa enfrentar situações "problema" e descobrir como fazer uso das TDIC de maneira realmente significativa.

Essas tecnologias têm transformado o espaço de convivência da escola e da sala de aula como, por exemplo, a organização dos tempos e espaços da escola, as relações entre o aprendiz e a informação, as interações entre alunos, e entre alunos e professor. Assim, a integração das TDIC nas atividades da sala de aula tem feito com o que é conhecido como blended learning ou ensino híbrido, sendo que a "sala de aula invertida" (flipped classroom) é uma das modalidades que têm sido implantadas tanto no Ensino Básico quanto no Ensino Superior (VALENTE, 2014).

Em conformidade com o entendimento de Valente (2014), é relevante esclarecer que o conceito de ensino híbrido (Blended Learning). Dessa maneira:

Entende-se por essa abordagem como sendo um processo de intersecção entre técnicas de aprendizagem convencionais e virtuais, apoiadas pelas tecnologias interativas. Em outras palavras, há uma combinação do aprendizado on-line com o off-line, em modelos que mesclam momentos nos quais os educandos estudam sozinhos (virtual), com outros em que a 


\section{DEVIR EDUCAÇÃO}

ISSN: 2526-849X

aprendizagem se dá na forma presencial. Além disso, tem-se uma valorização da interação entre pares e entre aluno e professor mediador (SOUZA, 2015, p. 44).

Adotando uma visão análoga, Moran (2015) afirma que híbrido significa misturado, mesclado, blended. A educação desde os primórdios foi misturada em diferentes tempos, atividades, espaços e com metodologias e públicos diversificados. Com as transformações sociais ocorridas nos últimos anos essa questão aparece ainda de maneira mais clara. Dessa forma, é possível ensinar e aprender de diferentes formas, momentos e espaços. "Híbrido é um conceito rico, apropriado e complicado. Tudo pode ser misturado, combinado, e podemos, com os mesmos ingredientes, preparar diversos "pratos", com sabores muito diferentes". (MORAN, 2015, p. 27)

Nesse sentido, o conceito de sala de aula invertida vincula-se a um tipo específico de Blended Learning (SOUZA, 2015, apud STAKER; HORN, 2012). Pois, "na Flipped Classroom, o aluno tem o primeiro contato com o conteúdo virtualmente, fora da escola, e posteriormente discute e tira dúvidas em sala (durante a aula)” (SOUZA, 2015, p. 44).

Interpolando uma posição mais completa, é possível acrescentar, em conformidade com Moura (2014, p,.1), que:

O conceito Flipped Classroom ou aula invertida, por exemplo, tem vindo a ganhar destaque na educação. (...) nas novas aprendizagens, os alunos passaram a realizar atividades e a solucionar problemas na aula. Esta abordagem diminui a importância dos conteúdos e do professor na sala de aula, em prol da resolução de exercícios, de trabalho de grupo e de atividades criativas na aula, estimulando a diferenciação da resolução de exercícios, de trabalho de grupo e de atividades criativas na aula, estimulando a diferenciação (MOURA, 2014, p.1).

Dessa forma, segundo Valente (2018) na sala de aula invertida, o aluno recebe o conteúdo e as instruções de forma on-line, antes do encontro ao vivo, na sala de aula física, essa interação só é permitida por pelo uso das TDIC, por meio de ambientes virtuais de aprendizagem. O facilitador, segundo o autor, é que sala de aula física se transforma em um lugar trabalhar os conteúdos já estudados remotamente, possibilitando a realização de atividades práticas, realização de projetos etc.

Segundo o autor supracitado, existem algumas regras a serem seguidas para inverter a sala de aula, são elas:

1. As atividades em sala de aula devem envolver uma quantidade significativa de questionamento, resolução de problemas e de outras 
atividades de aprendizagem ativa, obrigando o aluno a recuperar, aplicar e ampliar o material aprendido on-line. 2. Os alunos devem receber feedback imediatamente após a realização das atividades presenciais. 3. Os alunos devem ser incentivados a participar das atividades on-line e das presenciais, sendo que elas são computadas na avaliação formal do aluno, ou seja, valem nota. 4. Tanto o material a ser utilizado on-line quanto os ambientes de aprendizagem em sala de aula devem ser altamente estruturados e bem planejados. (VALENTE, 2018, p. 30)

Dessa forma, é possível observar que, ao contrário do que acontece na sala de aula tradicional, em que o aluno recebe um conteúdo e, posteriormente, faz as atividades e revisa em casa, na sala de aula invertida, o aluno já estudou em casa e, por isso, a sala de aula física torna-se um lugar de questionamentos, discussões e atividades práticas. Assim, "aula torna-se o lugar de aprendizagem ativa" (VALENTE, 2018, p. 29).

Percebe-se, nesse sentido, que na sala de aula invertida é levado em consideração o conhecimento construído pelo discente de maneira autônoma. "A consolidação da aprendizagem é, portanto, efetivada em sala de aula, na medida em que este espaço funciona como uma possibilidade de elucidação de dúvidas, problematização de questões em discussões fomentadas pelo conteúdo fornecido pelo professor-mediador" (SOUZA, 2015, p. 46).

Ao lado dessa metodologia surge outra questão bastante importante, a qual é importante levar em consideração, pois sabe-se que a grande maioria dos aparatos tecnológicos da atualidade surge como funções de entretenimento. Por esse motivo, parece ser necessário ampliar essa visão do senso comum, pois apesar que as tecnologias não tenham surgido com objetivo de trazer melhorias para educação, é possível utilizá-las nesse sentido e os estudantes precisam estar cientes desse fato.

O papel docente em meio a esse processo é essencial, pois o professor/mediador cumpre funções que são de extrema importância para o sucesso dessa metodologia em sala de aula. Por esse motivo, acredita-se que:

o professor desempenha um papel fundamental nesse processo, enquanto mediador das situações de aprendizagem com as quais os alunos estarão em contato, ainda que essas ocorram fora da sala de aula presencial. Na medida em que o professor opta pelo uso de dispositivos digitais móveis em seu programa de ensino, ele deve estar atento ao fato de que ter objetivos bem definidos será essencial para o sucesso das práticas a serem desenvolvidas. A finalidade pedagógica aliada ao uso responsável do dispositivo tecnológico devem ser bases fundamentais da filosofia de trabalho do professormediador. Além disso, ressalta-se que esse profissional deve estar preparado para trabalhar com os recursos tecnológicos a sua disposição. Ainda que o professor seja um pesquisador em serviço, aprendendo constantemente com 


\section{DEVIR EDUCAÇÃO}

ISSN: 2526-849X

a sua prática, ensinando a partir do que aprende, é necessário uma predisposição para atuar de forma gerencial e comunicacional, lidando com possíveis complicações que comumente aparecem por conta do uso de tecnologias digitais (SOUZA, 2015, p. 43).

A partir das reflexões propostas nesse excerto, é possível chegar à conclusão de que apesar de ser um grande desafio incluir um ensino híbrido, de modo mais específico, a sala de aula invertida no contexto escolar; parece existir uma nova demanda social, já que as tecnologias digitais têm mudado nossa maneira de ver o mundo e conviver no espaço social, sempre com a necessidade de otimizar o tempo e agilizar a vida. Por esse motivo, essa MA parece trazer uma resposta a essa geração e o desafio do docente é conseguir trazer as TDIC de maneira significativa e que traga ganhos no processo de ensino-aprendizagem.

\section{Considerações Finais}

O presente estudo teve como objetivo propor uma reflexão a respeito da formação continuada de professores voltada para o uso das TDIC e das metodologias ativas: sala de aula invertida e ensino híbrido e, a partir dessas reflexões, considera-se que, apesar de todas as dificuldades e empecilhos vivenciados pelos professores no cenário nacional, é possível que a escola e a universidade articulem em suas discussões experiências práticas na formação do profissional, de maneira a problematizar e simular problemas e situações da realidade, ensinando aos professores e estudantes a responderem questões práticas de suas profissões e a desenvolverem recursos para problemas futuros que poderão aparecer.

Dessa forma, utilizar às TDIC e às MA parece trazer uma nova concepção de metodologias de ensino, no sentido de abrir um leque de possibilidades e ainda oferecer maneiras de aplicar o conhecimento de forma mais contextualizadas. Assim, emprego das TDIC e das metodologias ativas pode favorecer a autonomia do estudante, despertando a curiosidade, estimulando tomadas de decisões individuais e coletivas, advindos das atividades essenciais da prática social e em contextos estudante.

Além disso, é importante que sejam introduzidas no contexto escolar discussões sobre os usos de tecnologias digitais que, mesmo que não tenham sido criadas com finalidades educacionais, elas podem e devem ser utilizadas para dinamizar, otimizar o tempo e facilitar a 
vida de professores e alunos. E, ainda que existam limitações quanto a utilização das M.A e das TDIC em sala de aula, reitera-se a relevância de uma constante atualização formativa, a qual deveria ser oferecida pelas instituições de trabalho (público ou privado) de forma gratuita e obrigatória.

Dessa maneira, a pretensão não foi de esgotar as possibilidades de aplicação das MA e das TDIC, mas sim, deixar uma porta aberta para que futuros pesquisadores também possam se propor fazer uso de recursos mais interativos, que possibilitem outros caminhos e outras visões.

\section{Referências Bibliográficas}

BAGNO, Marcos. Pesquisa na escola. Edições Loyola, 23º ed. 2009.

BARBOSA, E. F.; MOURA, D. G. DE. Metodologias ativas de aprendizagem na educação profissional e tecnológica. Boletim Técnico do Senac, v. 39, n. 2, p. 48-67, 2013.

BERBEL, N. A. N.. As metodologias ativas e a promoção da autonomia de estudantes. Semina. Ciências Sociais e Humanas (Online), v. 32, p. 01-25, 2011.

BRASIL. Secretaria de Educação Fundamental. Parâmetros curriculares nacionais: introdução aos parâmetros curriculares nacionais / Secretaria de Educação Fundamental. Brasília: MEC/SEF, 1997. 126 p. Disponível em: Acesso em: 11 jan. 2010.

FREITAS, V. P.; CARVALHO, R. B. ; GOMES, M. J. ; FIGUEIREDO, M. C. ; SILVA, D. D. F. . Mudança no processo ensino-aprendizagem nos cursos de graduação em odontologia com utilização de metodologias ativas de ensino e aprendizagem.. Revista da Faculdade de Odontologia. Universidade de Passo Fundo, v. 14, p. 163-167, 2009.

FREIRE, P. Pedagogia do Oprimido. São Paulo: Paz e Terra, 2006.

GEMIGNANI, E.Y.M.Y. Formação de Professores e Metodologias Ativas de EnsinoAprendizagem: Ensinar Para a Compreensão. Fronteiras da Educação (online), v. 1, p. 1-27, 2012. 
GERHARDT, Ana Flávia Lopes Magela. As identidades situadas, os documentos curriculares e os caminhos aberto para o ensino de língua portuguesa no Brasil. In AMORIM, Marcelo Álvaro, CARVALHO, Álvaro Monteiro (Orgs). Linguística Aplicada e Ensino: Língua e Literatura. Campinas, SP: Pontes,2013.p.77-113.

GOMES, A. P.; ARCURI, M. B. ; CRISTEL, E. C. ; RIBEIRO, R. M. ; SOUZA, L. B. M. ; SIQUEIRA-BATISTA, R. . Avaliação no Ensino Médico: o papel do portfólio nos currículos baseados em metodologias ativas. Revista Brasileira de Educação Médica (Impresso), v. 34, p. 390-396, 2010.

IMBERNÓN, Francisco. Formação continuada de professores. Porto Alegre: Artmed, 2010.

LÉVY, Pierre. O futuro da internet: em direção a uma ciberdemocracia planetária. SãoPaulo: Paulus, 2010. _. Cibercultura. São Paulo: Editora, v. 34, 1999.

LIBÂNEO, José Carlos. Adeus professor, adeus professora? Novas exigências educacionais e profissão docente. 12. ed. São Paulo: Cortez, 2010. quê? 10. ed. São Paulo: Cortez, 2008. Pedagogia e pedagogos, para

MAGALHÃES, Luciane Manera. Modelos de educação continuada: os diferentes sentidos da formação reflexiva do professor. A formação do professor: perspectivas da Linguística Aplicada. Campinas, SP: Mercado de Letras, p. 239-259, 2001.

MITRE, S. M. et al. Metodologias ativas de ensino aprendizagem na formação profissional em saúde: debates atuais. Ciência \& Saúde Coletiva, v. 13, p. 2133-2144, 2008.

MORAN, J. M. Mudando a educação com metodologias ativas. Coleção Mídias Contemporâneas. Convergências Midiáticas, Educação e Cidadania: aproximações jovens, Vol. II, Carlos Alberto de Souza e Ofelia Elisa Torres Morales (orgs.). PG: Foca Foto-PROEX/UEPG, p. 15-33, 2015.

MORAN, José Manuel. Educação inovadora na Sociedade da Informação. ANPEDE. São Paulo, 2006.

SILVA PINTO, S. A.; et al. Inovação Didática-Projeto de Reflexão e Aplicação de Metodologias Ativas de Aprendizagem no Ensino Superior: uma experiência com "peer instruction”. Janus, Lorena, ano 6, n. 15, 1jan./jul., 2012.

SOUSA, Maria Goreti da Silva. A formação continuada e suas contribuições para a profissionalização de professores dos anos iniciais do ensino fundamental de TeresinaPi: revelações a partir de histórias de vida. 2008, 130 f. Dissertação (Mestrado em Educação UFPI)

SOUZA, C. F. Aprendizagem sem distância: tecnologia digital móvel no ensino de língua inglesa. Revista Texto Livre, v. 8, p. 39-50, 2015. 
VALENTE, José Armando. A comunicação e a educação baseada no uso das tecnologias digitais de informação e comunicação. UNIFESO-Humanas e Sociais, v. 1, n. 01, p. 141166, 2014.

VALENTE, J. A. A sala de aula invertida e a possibilidade do ensino personalizado: uma experiência com a graduação em midialogia. Metodologias ativas para uma educação inovadora: uma abordagem teórico-prática. Porto Alegre: Penso, p. 26-44, 2018.

VALENTE, José Armando et al. O computador na sociedade do conhecimento. Campinas: Unicamp/NIED, v. 6, 1999.

VALENTE, J. A. Blended learning e as mudanças no ensino superior: a proposta da sala de aula invertida. Educar em Revista, Curitiba, Brasil, Edição Especial n. 4/2014, p. 79-97. Editora UFPR.

VOLPI, Marina Tazón. A formação de professores de língua estrangeira frente aos novos enfoques de sua função docente. $O$ professor de línguas estrangeiras: construindo a profissão. Pelotas: Educat, p. 125-133, 2001.

WALL, M. L.; PRADO, M. L. ; CARRARO, T. E. A experiência de realizar um Estágio Docência aplicando metodologias ativas. Acta Paul Enferm. 2008;21(3):515-9. 